\title{
Design of production systems with hybrid energy and water generation for sustainable value creation
}

\author{
S. Emec $\cdot$ P. Bilge $\cdot$ G. Seliger
}

Received: 25 June 2014/ Accepted: 23 March 2015/Published online: 25 July 2015

(c) The Author(s) 2015. This article is published with open access at Springerlink.com

\begin{abstract}
Population growth, connected with rising incomes, urbanization, fidelity to dogmas and climate change, places pressure on the food industry. This significantly increases the inextricably-linked demand of production systems for water and energy. Technological solutions-such as increasing accessibility and further reducing costs — can be employed to overcome the limitations created by the local availability of resources. This paper develops a new methodology generating sustainable value, and thus achieving a competitive advantage in business ecosystems. The methodology addresses both the key requirements of sustainable development and the preferences of stakeholders. A set of design conditions are proposed to develop eco-efficient, socio-eco-effective, and adaptable production systems under changing limitations. An international project is launched to demonstrate the superiority of the design methodology and to create awareness about interdependencies among the prevalent design conditions and regional limitations. The task aims at developing technological solutions, which can be retrofitted in existing production systems to increase the sustainable local added value and capacity for regions affected by climate change. The impact of climate change is more obvious in semi-closed ecosystems. Cyprus is one of the Mediterranean islands with such a semi-closed ecosystem. Combined with water scarcity and rising prices in electricity, this made Cyprus an ideal testing ground for the
\end{abstract}

\footnotetext{
S. Emec

Department of Industrial Automation Technology, Berlin Institute of Technology, 10587 Berlin, Germany

P. Bilge $(\bowtie) \cdot$ G. Seliger

Department of Machine Tools and Factory Management, Berlin

Institute of Technology, 10587 Berlin, Germany

e-mail: bilge@mf.tu-berlin.de
}

methodology. The selected solution includes the use of hybrid energy and water generation to process agricultural products and to recycle organic waste. This solution achieves a nearly zero emission, zero water footprint and increases the local added value by product-service systems. To support decision-makers, various technologies and their feasibility are considered, evaluated and recommendations are made for implementing the modular solutions.

Keywords Production systems - Eco-efficiency - Socioeco-effectiveness $\cdot$ Energy water nexus $\cdot$ Design methodology $\cdot$ Sustainable value creation

\section{Introduction}

Presently, more than $10 \%$ of worldwide population is undernourished due to lack of food. $30 \%$ do not have access to safe water and $20 \%$ still lack access to electricity (WWAP 2014), while $0.7 \%$ of the worldwide population own $41 \%$ of all global assets (Shorrocks et al. 2013). Taking into account the predicted population growth by 2030, food demand is expected to increase by $50 \%$, while energy demand from hydropower and other renewable energy resources will rise by $60 \%$ (WWAP 2014). Global economic growth and individual wealth create a shift in diets from predominantly starch-based to meat- and dairy products-based, which require more water to be produced. Globally, $70 \%$ of the fresh water supply is utilized by the agriculture sector, while industry uses only $22 \%$. The agricultural, food production, and supply chain sectors account for about $30 \%$ of total global energy consumption (FAO 2011). Taking that into account, world manufacturing energy consumption is projected to increase by $44 \%$ between 2006 and 2030 (Abele et al. 2008). However, the 
current availability of water and energy as resources per se is not a global problem. The situation changes significantly when local water quality is considered. $85 \%$ of the world population lives in the drier half of the planet. The Intergovernmental Panel on Climate Change predicts with high confidence that water stress will dramatically increase in central and southern Europe, and that by 2070, the number of people affected by the water scarcity will double. Summer flows are likely to drop by up to $80 \%$ in southern Europe (Alcamo et al. 2007). California (situated within the same circle of latitude as Cyprus) is already facing major water shortage, an alarming trend which exemplifies the forecasted impacts for central and southern United States.

The question whether climate change is caused by human activity or by natural cyclical phenomena cannot be answered for sure. The fact is that the acceleration of climate change already affects economics. It results in damage to property and infrastructure, lost productivity, mass migration and security threats. The deceleration of climate change and the reduction of economic effects can be achieved through sustainable value creation. This leads to carbon-based production which runs on renewable and non-renewable resources in closed cycles. The design, assessment and maintenance of such production systems within the limitations of sufficient renewable generation and social compatibility are the major challenges of the twenty-first century.

Industry in the early twentieth century is characterized by economies of scale through reduction of average costs, coupled with efforts to increase the flexibility and the efficiency of production systems. The focus of production system design has moved from efficiency to effectiveness in the last decades. Economies of scope, efforts to increase effectiveness and ability for adaptation of production systems characterize the period from late twentieth to early twenty-first century. Awareness of this paradigm shift is essential for decision-makers to enable technological innovation and to develop assessment approaches which ensure both effectiveness and efficiency already in the design stage of production systems. Information and communication technologies (ICT) are exploited to change and assess current production systems (Jovane et al. 2008). Most approaches only assess the environmental impact of total life-cycle leaving out the economic and social effects. A uniform set of measures for assessment can rarely be found in either literature or practice. The efficiency of performed activities can be assessed according to separate economic, environmental or social impacts. By comparison, effectiveness is assessed based on multiple impacts and their interrelations which are defined as effects of technological solutions on ecosystems. Multiple perspectives should be considered in order to assess the effectiveness of goal achievement. These perspectives will increase the assessment results' quality. The assessment procedure is a central part of continuous improvement in all planning, design and operating activities. Despite the prevalence of financial and utilization targets in production, there is a lack of standardization for integrative assessment approaches. Future research in assessment must focus on this lack to increase effectiveness, while also being efficient.

The overall goal of this paper is to present a design methodology for the sustainable development of production systems. The following methodology is proposed in order to address this goal by answering the following questions: what needs to be fulfilled? Key requirements for value creation are derived from the sustainable development goal in "Sustainable development" section. How can sustainable value creation networks be shaped? The value creation architecture presented in "Design conditions for sustainable production systems" section provides a framework for how to best utilize the dynamics of competition and cooperation to achieve sustainable development. The authors review organizational structures, examining design concepts in order to discover how value creation is shaped within this framework. Design conditions to meet the key requirements are defined as functional needs, which a production system must be able to perform. Preferences are discussed as subjective ranks of functional needs.

What are the challenges to meeting the key requirements? Production systems are delimited by permeable boundaries, across which technologies can create value to satisfy functional needs. The space outside of boundaries including economic, environmental and social aspects is known as ecosystem. The functional needs for production systems determine boundaries, which limit activities within the ecosystem. To demonstrate the superiority of the proposed design methodology within limitations such as resource availability, the island of Cyprus-specifically, North Cyprus-was selected for a case study, as presented in "Increase of local added value in Cyprus" section. The task is to increase local added value through sustainable technological solutions. What are the technological solutions? Using a deductive case study, potential technological solutions are explored, simulated and validated. The most appropriate technological solutions were then integrated into a production system. Have the key requirements been satisfied? Attributes are determined to assess the fulfillment of key requirements through technological solutions in "Assessment of methodology" section. An assessment approach is developed to establish whether the proposed production system fulfills the intended goal of sustainable development and maintains competitive advantage. Which technological solutions should be implemented? Based on 
the assessment results, recommendations are given for Cypriot implementation in "Conclusions" section.

\section{Sustainable development}

This section examines the requirements in manufacturing in order to determine under which conditions and with which tools sustainable development can be ensured. The term sustainability was first used by the engineer and forest scientist Carlowitz in 1713. He aimed to address the challenge of an increasing national wood shortage by maintaining wood supply for large-scale mining. The principle of sustainable forestry is formulated from an intergenerational perspective by Hartig, a forestry lecturer in Germany, in 1804: "Every wise forest director has to have evaluated the forest stands without losing time, to utilize them to the greatest possible extent, but still in a way that future generations will have at least as much benefit as the living generation." (Schmutzenhofer 1996). For Hartig, assessing the global wood shortage is instrumental for providing recommendations for local action.

Kant's categorical imperative from 1785 declares "Act only according to that maxim whereby you can at the same time will that it should become a universal law without contradiction" (Johnson 2008). The categorical imperative can be interpreted as a moral obligation more than as a recommendation to perform value creation only according to that maxim which can be a universal principle without compromising current and future well-being. The requirements for sustainable forestry, as well as the moral obligations, are both reflected in ethical values. Ethical considerations are inherent in or result from education or experience. They raise awareness and establish principles which remain valid under changing conditions. Human activities are primarily determined by ethical values, as well as by limitations of ecosystem and local opportunities. Graedel identifies similarities between the behavior of biological organisms and the behavior of industrial organisms. He proposes that the classic way in which biological organisms interact with other biological organisms can be transferred to industrial organisms and their interactions (Graedel 1996). Following Graedel's lead, this paper aims to design sustainable production systems which mirror the interactions of ethically-driven biological organisms.

An ecosystem consists of at least two interacting stakeholders and environmental factors, which shape the stakeholders' economic, as well as social freedom of action. The primary environmental factors are availability of energy and water resources, the climate including parent materials, which shape the soil, establish the topography and impose limitations. Local opportunities, as characterized by Bloch, are (1) the ability for value creation under existing limitations and (2) value creation considering the unknown factors and forecasting for climate, as well as energy and water availability. The relations between ecosystem, market economics and decisionmaking are summarized as "Think global, act local" by Geddes in 1915 (Agudelo-Vera et al. 2011). Geddes' requirement implies that the knowledge to assess which values under global constraints determine the preferences for local action. The overall goal to perform actions for local value creation without compromising current and future global well-being is derived from Kants categorical imperative. However, the scope for action, the conditions and the constraints are not specified. Acting locally presupposes understanding the limitations of the ecosystem. To this extent, Geddes proposed three steps for the development of regional actions: (1) preparation of a local survey; (2) analysis of the survey regarding the implementation; (3) development of the action plan. These three steps are integrated as the inductive creative process in the design methodology and applied as a case study in "Increase of local added value in Cyprus" section.

In the 1970s the Club of Rome promoted the study 'The Limits of Growth' which paved the way for the green industrial revolution. The 'Brundtland Commission Report' of the United Nations, published in 1987, introduced the term sustainable development and promoted the change of technological, economic and social systems (Brundtland 1987). In brief, the term sustainable development signifies the process of meeting the needs of the present without compromising the ability of future generations to meet their own needs. Increased well-being must benefit the majority of the society (Seliger 2007). What used to be a single focus on economic growth, environmental limitations or human development is extended. This report stipulates that sustainable development is the overall goal of the United Nations, governments, research institutions, private organizations and companies. This overarching, global goal calls for competitive and sustainable manufacturing as enabler of products, services and processes (Jovane et al. 2008).

Building upon the concept of sustainable development, the 'Enquete-Commission' introduced in 1998 the triple bottom line of economic, environmental and social effects (Seliger 2007). (1) The economic impact is estimated according to lean thinking by improving quality, reducing costs and eliminating waste. (2) The ecological or environmental impact covers consumption of materials and energy resources, as well as detection of emissions. While the term 'ecological' focuses more on the science of relationships between organisms and their environment, 'environmental' is more related to the impact of human activity on both environment and society (Oxford 
University 2014). (3) The societal or social impact relates to corporate social responsibility. Qualified decision-makers need to be aware of these global challenges in order to promote the improvement of design, assessment and implementation of technological solutions.

Sustainable development can promote technological solutions to ensure mankind's survival and further development in spite of limited resources while stimulating global well-being. The global growth rate coupled with changing environmental conditions triggered by climate change puts pressure on regional value creation. This situation decreases the competitiveness of conventional food industries and requires a paradigm shift in production systems. Entrepreneurs face a challenge to continuously review the economic, environmental and social effects on production, and if necessary, to make changes. Sustainable development must be conceived as a common goal of companies, while maintaining a superior position in the market through achievement of intended company goals. Establishing win-win-situations also contributes to the success of all stakeholders. Entrepreneurs must be aware of the efforts and requirements necessary to achieve consensus. Applying the appropriate technological solutions, business success and sustainable development is a reasonable goal.

Whether a production system is able to ensure these goals is measured by its performance in managing the transition to sustainable production. Performance describes the effect of how successfully a specified task is completed and an activity fulfilled (Hauschild 2014). Measuring the performance of an activity supports decision-making. Assessment is the procedure of collecting, analyzing and reporting information about activities as they pertain to meeting requirements. Approaches searching for an optima, such as simultaneous planning, would typically fail since they disregard stakeholder preferences and the interactions among them (Schuh et al. 2007).

As proposed by Carlowitz, the extent to which time, cost and resources are used is described by efficiency. It seeks to do more with less, e.g., through increased speed with less resources and waste. Efficiency is expressed as inputoutput ratio of the capability to 'do an activity right'. Effectiveness seeks to 'do the right activity'. It is the capability of creating the intended value for mankind, as proposed by Kant. Effectiveness must be learned and trained (Bilge et al. 2014). While effectiveness questions the goal, efficiency stipulates the amount of resources and time needed to reach the goal.

The industrial revolution of sustainable development addresses the major shortcomings of efficiency and effectiveness. Many companies and current research approaches work based on approximation and do not consider interactions between economic, environmental and social effects: measuring profit quantifies the economic impact. Tracking carbon and water footprint applies life-cycle analysis methods to quantifying environmental impact. The establishment of ergonomic workplaces for workers can be quantified by social and economic impacts. Integral approaches will move beyond these separated impacts by focusing on the broader identification of technological potential and the increase of competitive advantage.

A competitive advantage is achieved if a company gains a superior business position through an activity (Porter 1998). Enabled by information and communication technologies (ICT), product-service systems (PSS) as a business approach encourages a competitive advantage with less resource consumption. PSS provides more added value by selling functionality and services rather than tangible products (Seliger 2011). This definition primarily increases efficiency by generating more added value with the input of fewer resources. To also increase effectiveness, functionality and services should be designed so as to establish a win-win-situation for all stakeholders: for customers who would pay less; for companies which would benefit more; and for the ecosystem, by consuming less resources for the same or additional functionality.

Fulfilling managerial tasks is made difficult by changing ecosystems, and thus requires appropriate decision making. This is enabled by ICT with worldwide access to knowledge and environmental measurements. Company strategy influences preferences for decision-making and allocation of resources required for achieving overall goals (Chandler 1990). The Balanced Scorecard (BSC) is an acknowledged management tool based on financial and non-financial data. The BSC translates the company strategy into a set of qualitative requirements and quantitative measures that support future improvement including targets and initiatives. The Balanced Scorecard is applied for the derivation of requirements from goals. The following seven key requirements are identified as goals to initiate sustainable development: (1) creation of awareness, education and training are needed to determine sustainable solutions. (2) Sustainable development must contribute to competitive advantage ensuring business success. (3) A win-win-situation for stakeholders must be stimulated, while retaining competition on the market. (4) Continuous review and improvement of value creation activities depends on the target deployment. (5) Continuous improvement can also check if the performance can be increased through less resources, higher speed and less waste. (6) Resource productivity must be increased by creating new added value.

(7) Rapidly changing conditions must be met with appropriate adaptation to increase the probability of system survival.

It must be determined to which extent the design of technological solutions can contribute to achieving the 
aforementioned key requirements (Smith and Ruiz-Mercado 2014). An assessment approach is proposed to check if sustainable development and competitiveness can be simultaneously achieved by the presented design methodology. The intention is to assess the value creation through a set of descriptive and measurable characteristics. Attributes are defined as characteristics, which indicate the current position or the direction and rate of change toward a particular goal (Bilge et al. 2015). Multi-attribute utility theory (MAUT) enables decision-makers to structure complex systems in a hierarchical form, as well as to assess measures in the presence of uncertainty (Bilge et al. 2014). MAUT manages trade-offs in value creation by combining different perspectives and quantifies individual stakeholder preferences. Life-cycle analysis (LCA) tools assess the performance of life-cycles and provide measurable values, as well as data structure, primarily in order to determine the direction of economic, environmental and social impacts. ISO 14000 and ISO 14044 provide widely used guidelines for LCA studies (DIN 2009).

Following the proposed design methodology, value creation must be continually reviewed to develop technological solutions and create more added value while also meeting the key requirements. This review presents tools for an integral approach exploring how technological solutions can be compared and assessed to provide feedback and continued improvement for the design. The Balanced Scorecard provides the methodology for the transformation of overall goals into requirements and attributes to frame the design procedure. MAUT is applied to attributes in order to rank technological solutions and validate their effectiveness. LCA provides the identification of measures for attributes to verify the efficiency of technological solutions. The combination of MAUT and LCA integrated into the design methodology identifies descriptive values and measures to close an iterative loop for new technologies through continuous improvement. The next section presents a model of how to translate key requirements into a value creation architecture and the resulting conditions needed to design production systems.

\section{Design conditions for sustainable production systems}

This section introduces a framework for the development of sustainable production systems. After clarifying the question of what is to be fulfilled by key requirements, the next step is to identify how to fulfill the key requirements during the design and assessment stage of production systems. To frame the field of action, localize and characterize stakeholders, as well as determine the impacts, a value creation architecture is presented. The organizational structures are reviewed and design conditions are specified as functional needs, which a production system must be able to perform. The following questions guides the methodology: (1) which value creation architecture considers economic, environmental and social effects? (2) How can the dynamics of competition and cooperation in globalized markets be utilized by innovative technologies? (3) How can production systems be classified according to design concepts? (4) Which design conditions must be fulfilled in the field in order to achieve the key requirements of sustainable development?

\section{Value creation architecture}

This section aims to describe the architecture of value creation networks, which provides a map where production systems can be clustered according to production depth under economic, environmental and social effects. Value is a measure of economic, environmental and social benefits created within the transformation of raw materials or applied services. If the ratio between raw materials as resources, from input to output, is changed, this value adding processes is called production. Production is primarily the physical transformation of raw materials into semi-finished or finished products. Both discrete and continuous manufacturing use energy and water for this transformation. Discrete manufacturing is characterized by its use of primarily mechanical and strain energy; while continuous manufacturing, by chemical and thermal energy (Segreto and Teti 2014). The process of value adding is interpreted as a transfer function describing the inputs and outputs. The required factors for creating the added value in products are process-, equipment-, organization- and human- related.

The challenges of global value creation refer to a range of production activities from realizing technological innovation over modeling and planning to assessment (Seliger 2011). Figure 1 shows an approach of how to model these challenges. The factors and their interactions shape a single value creation module (VCM) on the top-left side. A VCM must be assessed considering its economic, environmental and social effects on the total life-cycle (Seliger 2007).

1. What should be produced? Product refers to which material in what quantity should be processed through the value creation chain and to the quality required. A product can be a tangible and physical object or a service of completing a task. Products are specified by type, function, geometry and structure (Suh and Do 2000).

2. How should it be produced? Process is defined as the use of one or more physical mechanisms employed to transform the shape, form and properties of a material 
Fig. 1 Value creation architecture (CRC 2013)

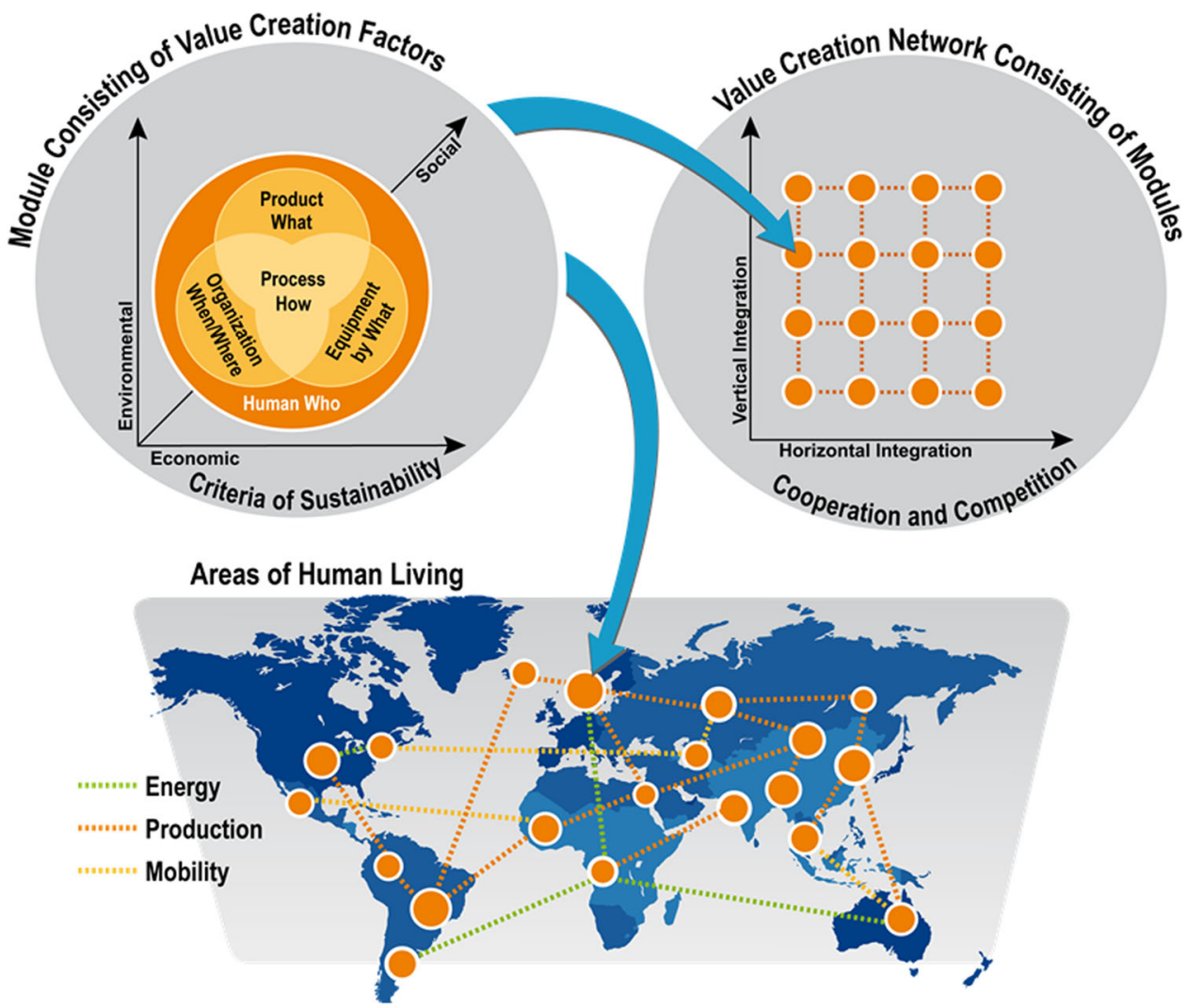

(Alexopoulos and Chryssolouris 2014). Processes consider how to create products through existing technologies that should be utilized to add value. Assembly, transport, recycling and maintenance activities are some examples of processes.

3. By what means should it be produced? Equipment relates to machines and tools that are used to run the processes successfully at the required operational conditions and reliability levels. Machine tools, robots, transport and information represent typical production equipment.

4. When and where should it be produced? Organization deals with the procedural, structural and managerial decisions about when, where, and which processes, with which equipment, for which product, should be run. Organization addresses management and operational activities such as production planning and control. It includes the quantitative and capacitive flow of materials, energy, water, finance and information, as well as supply chain management.

5. Who should produce, supervise and manage? Companies are required to satisfy shareholders' needs by making profit. The factor Human relates to the assignment of tasks to and the involvement of stakeholders. Satisfaction of external stakeholders' expectations ensures the accomplishment of success and achievement of long-term goals such as sustainable development. Awareness, qualification and training skills are needed for decision-makers, employees and operators to complete their tasks.

A single VCM in vertical and horizontal relation with others forms a network. Multiple modules make up a value creation network, as shown on the top right side in Fig. 2. A network is a mathematical model and represents the availability of production systems. The location of value creation modules in the network is determined by product type, production depth, production capacity and lead time.

The architecture provides a framework to simplify the complex dynamics of competition and cooperation in value creation networks. The dynamic relations between value creation modules shape the production systems and determine the limitations of the ecosystem. These interactions are explored for different design conditions. Design concepts serve as a model to classify production systems in the next section.

\section{Classification of production systems}

The classification of organizational structures in value creation networks is used to examine design concepts and identify how to shape production systems within the 
presented architecture. A supply chain is a sequence of jointly operated value creation modules. Cooperation between suppliers, manufacturers and consumers generates a win-win-situation. It also supports the planning, execution and monitoring of material and information flows in a supply chain. Modules in a supply chain, which perform an added value in material transformation, are vertically integrated in the value creation network. The vertical integration depicts the production depth and specifies the production processes, while horizontal integration depicts the production breadth and specifies the product type. Horizontally related modules in a network mostly compete with each other to gain business success (Seliger 2011). Competition between market players is created when they consume various raw and auxiliary materials as input in order to produce a similar type of output within a single VCM on the same production depth.

The earth in conjunction with the sun offers resources. The consumption and conversion of resources build a highly complex system, also called an ecosystem. As presented in Fig. 2, an ecosystem encircles value creation networks and sets limits for requirements. Interdependencies between limitations and responding preferences determine boundary conditions, as depicted by the blue line. Value creation networks can be divided into smaller parts. Each part for a particular goal, consisting of one or more modules is described as a production system. A production system includes discrete and continuous manufacturing systems, as well as energy generation systems. It combines vertical and horizontal interacting value creation modules (VCM) to achieve goals predefined by stakeholders. It can be split into many supply chains according to supplier and customer cooperation (Pahl et al. 2007).

Boundary conditions are related to the modules' location as parts of one production system in the network. Rapidly

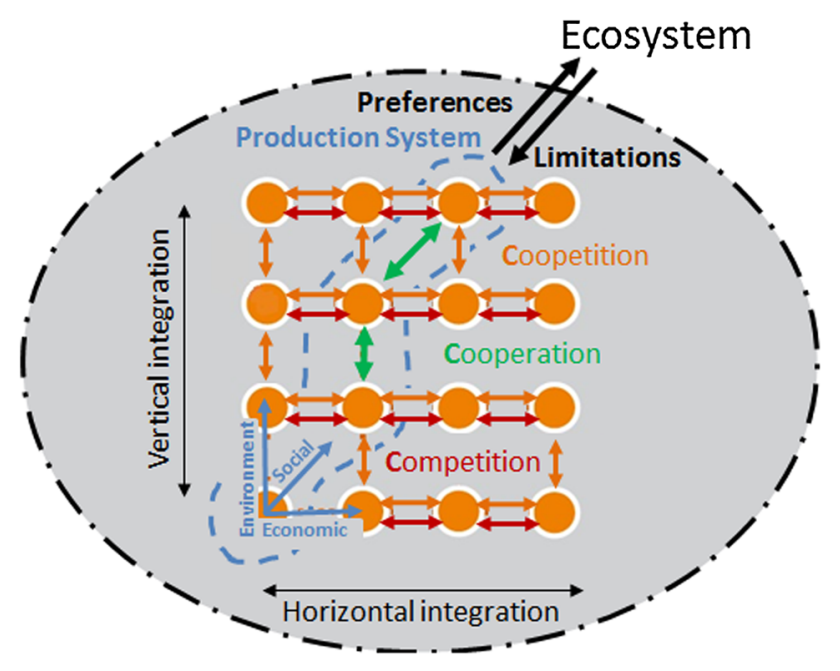

Fig. 2 Model of production system and limitations changing conditions must be met with adaptation. Under consideration of economic, environmental and social effects, more efficient and effective modules can be substituted for current modules. The new modules can have similar, though not identical, specifications to the current modules (Porter 1998). The exploration of new technologies is not part of current production systems; however, it does represent emerging modules within the network. The diffusion of emerging modules affects the boundary conditions of production systems by increasing competiveness. Other than in a supply chain, horizontally integrated competitors can cooperate in a production system. The cooperation between competitors is called coopetition, which aims to pursue a superior goal through a win-winsituation.

The dynamics of cooperation, coopetition and competition between stakeholders shape the depth and breadth of production. These interactions, preferences and local limitations specify the design of production systems. Production systems are classified here according to design concepts. A design concept refers to a development procedure according to predefined specifications of a production system. Specifications must be feasible and have the potential to fulfill key requirements (Christophe et al. 2014). The axiomatic design approach presented by Suh describes design as a three-step process: (1) problem definition which results in the definition of key requirements and design conditions; (2) the creative process of conceptualizing and devising a solution which is extended within the developed design methodology; (3) the assessment of determining if the proposed solution is a rational solution which is consistent with the problem definition as presented in "Assessment of methodology" section (Suh and Do 2000).

An integral design methodology is developed in this paper to combine top-down and bottom-up approaches by enabling sustainable value creation: (1) the top-down analysis of the current production systems starts from the framework of value creation and cascades to modules and factors, the design of which corresponds to a case-study. This creative deductive process conceptualizes and models technological solutions considering key requirements of sustainable development and design conditions as they are presented in the next sections. (2) "Increase of local added value in Cyprus" section represents the bottom-up process of analyzing preferences and measuring local limitations to devise technological solutions. The creative inductive process starts by simulating various configurations with slight changes through evaluating which configuration can provide the most sustainable and competitive solutions.

The design of production systems is classified by functional and organizational distribution: (1) functional groups within a company are built according to main activities 
such as procurement, production, sales and finance (Abele et al. 2008). Control across multiple groups is limited. Currently, there are relatively few tools to monitor and provide decision-support for cooperating stakeholders in the supply chain, as well as for production systems. Existing tools for enterprise resource planning (ERP) provide companywide support for decision-makers rather than for selecting, e.g., a market player for coopetition and designing a PSS. However, specialized skills are utilized efficiently in production depth. (2) Companies are organizationally distributed by product types and regional added value. The more decentralized the facilities are, the more the supply chain covers a large production breadth (Mourtzis et al. 2012). Based on geographic distribution of facilities and the significance of local adaptation, five subclasses are identified (Abele et al. 2008):

(2a) World factory provides a centralized production system with either one or very few facilities for industries with major economies of scale and scope. (2b) Hub and spoke provides centralization for knowledge-intensive value creation modules in a few facilities and demonstrates economies of scale for specific products. Further products are distributed to a large number of facilities close to the market. This enables delivery of products with many variants. (2c) A Sequential network maximizes economies of scale and the scope for each value creation module. However, the high international transaction costs limits its implementation. (2d) Web structure provides smooth capacity utilization despite volatile demand in decentralized networks. It supports balancing production capacity across facilities with a sophisticated supply chain flexibly. (2e) Local for local provides decentralized value creation, which is suitable for market-specific products with strict delivery requirements. This increases the flexibility of production systems and enables a variety of both PSS and coopetition. However, economies of scale are barely used and decentralized facilities have relatively few interactions.

These five classes represent recommendations of how to structure the value creation network according to regional preference and limitations. As mentioned previously, under dynamic changing limitations, adaptability of production systems is required. Modular designed systems can be created independently, then adapted and implemented with multiple functionalities following the principle "local for local" (Tseng and Wang 2014). The network can be divided into independent modular designed production systems following the principle of mini-factories (Postawa et al. 2011). Mini-factories require high flexibility to be customized for various material and energy flows in different locations. The more adaptable the mini-factories are, the more independently they can operate locally and meet customer needs.

In manufacturing, production systems are typically designed from cradle-to-grave, which is also known as open-loop. The value stream involves suppliers and customers from resource extraction (cradle) over the use phase to the disposal phase (grave). Cradle-to-grave does not fulfill the key requirements such as no longer disposing of non-renewables by consequent adaption and their substitution with renewables. However, sustainable manufacturing closes the loop from cradle-to-grave to cradle-to-cradle, also called closed-loop. The 6Rs (Reduce, Reuse, Recycle, Recover, Redesign, and Remanufacture) suggest how to close the loop through total life-cycles (Jawahir and Dillon 2007). During the second life-cycle, the 6Rs approach reduces resource consumption through waste minimization. Recover refers to processes to disassemble, sort and clean materials, as well as stand-alone products at the end of their use stage. Product redesign simplifies future post-use processes through design techniques (Duflou et al. 2012). Remanufacturing is the re-processing of used products for restoration to their original state or to a new form through the reuse of components without loss of functionality (Jayal et al. 2010).

Production systems as part of value creation networks are described according to structure properties, preferences and limitations. The presented design approach extends axiomatic design, including both deductive conceptualizing and the inductive process of devising technological solutions. The inductive process considers the regional stakeholders' preferences and limitations. The traditional relations of stakeholders on the market are extended from cooperation and competition to include coopetition, which is introduced as a win-win-situation between competitors. Coopetition between competitors needs to be stimulated to ensure the efficient use of resources. For the case study in Cyprus, value creation networks can be stimulated by modular mini-factories to increase the coopetition, gain flexibility and to be customized on different locations for various material and energy flows. To use resources effectively, material cycles should be designed from cradle-to-cradle. To develop an integral design methodology for sustainable production systems, conditions must be specified based on key requirements. Key requirements are presented following the deductive conceptualizing of design conditions to ensure eco-efficiency and ecoeffectiveness.

\section{Eco-efficiency and eco-effectiveness}

The following key requirements are essential for the improvement of environmental impact and resource productivity: value creation activities need to be continuously reviewed depending on the target deployment. New technologies and processes need to be continuously developed to increase performance with less resources, higher speed and less waste. In order to identify the optimal design 


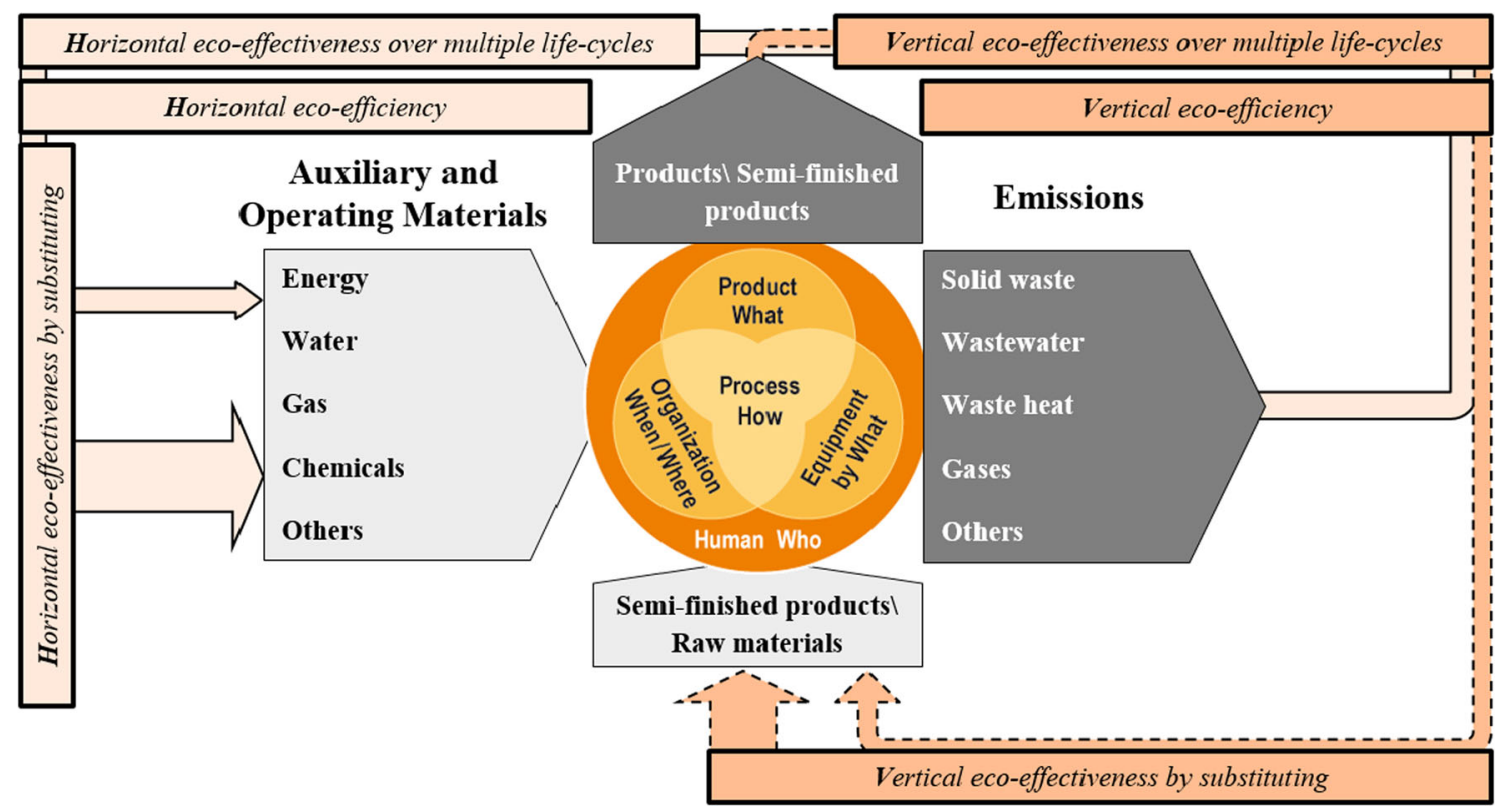

Fig. 3 Eco- efficiency and eco-effectiveness in material and energy flows (Emec et al. 2013)

conditions of how to shape the interfaces of VCMs, material and energy flows in production systems are examined. The guiding question is which design conditions must be fulfilled on the level of VCMs to achieve these key requirements. If each VCM in a production system can achieve this goal, it is to be expected that the value creation network will follow suit.

Figure 3 presents a qualitative input-output-analysis for the energy and material flows of a VCM. The transformation of raw materials into products is presented vertically. The alteration of auxiliary, operating materials and energy resources into waste, emissions and disposables is presented horizontally. Eco-efficiency is the ratio between the finished product as output and the resource as input of a value creation module. Eco-effectiveness is the continuous review and improvement of goals to develop and implement technologies (Emec et al. 2013). Both improve environmental impacts in economic terms. Eco-efficiency can improve environmental impacts through implementation of new technologies to generate, e.g., less wastewater and $\mathrm{CO}_{2}$ emission (Bleischwitz and Hennicke 2004). Ecoeffectiveness can improve environmental impacts by applying the cradle-to-cradle concept. This design concept expects materials to maintain their status as resources and to accumulate intelligence over time by generating multiple life-cycles (Braungart et al. 2007).

Six design conditions are determined to serve the two key requirements above, which promote eco-efficiency and eco-effectiveness. Eco-efficiency as such is improved through innovative methods and technologies (1) vertically for more finished products with less raw materials in shorter time and (2) horizontally for less emissions with less auxiliary and operating materials. Eco-effectiveness is increased by (3) no longer disposing non-renewable waste and end-of-life products vertically and (4) no longer disposing non-renewable auxiliary and operating materials horizontally through consequent adaptation for multiple life-cycles from cradle-to-cradle. The socio-eco-effectiveness is increased through (5) substituting non-renewable raw materials vertically and (6) substituting non-renewable auxiliary and operating materials horizontally with renewables, within the limitations of sufficient renewable generation and social compatibility.

To increase the eco-efficiency and socio-eco-effectiveness of any VCM, changing limitations and different

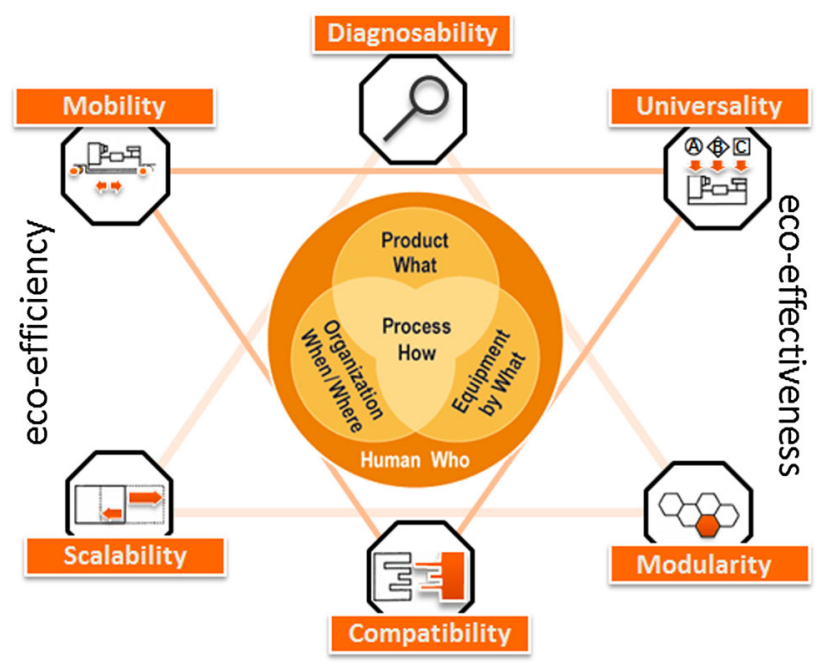

Fig. 4 Flexible and adaptable value creation modules (Emec et al. 2013) 
preferences must be satisfied. The next step is to determine design conditions for the appropriate adaptation of VCMs to a particular goal. It is essential to examine how the VCM can fulfill the key requirement.

\section{Changeability}

Changeable manufacturing is defined as the ability of a production system to accomplish the necessary adjustments of the value creation factors and modules in quick response to changing impulses (ElMaraghy and Wiendahl 2014). Changeability in production systems can be divided into two classes: flexibility and adaptability. The appropriate adaptation to changing conditions and limitations increases the probability of a system's survival (Emec et al. 2013).

The aspects of flexibility and adaptability that Wiendahl introduced are identified as six design conditions for VCMs, and presented in Fig. 4 (Wiendahl et al. 2007): (1) the universality of modules refers to the fact that certain properties do not depend on every system detail. Production systems can consist of VCMs with different lead time and still create similar products. (2) Modularity requires standardization, pretested modules with standardized interfaces and facilities, as well as an organizational structure. Modules are autonomously working units or elements that ensure high interchangeability with less cost or effort. Modular designed production systems are composed of standardized individual modules according to predefined interfaces. (3) Compatibility allows the manifold integration of a module into production systems. (4) Scalability allows for a better response to an increase in demand through connected modules creating similar types of products. (5) Mobility is required for the ability of the module to provide services such as availability of auxiliary materials, e.g., energy and water generation through renewables and easily transportable container design. (6) Diagnosability is the process to determine parameters that can indicate, for example, product quality and equipment condition in time and place.

The five factors shape the VCM, including the vertical and horizontal edges connecting the nodes, which are represented by design conditions for flexibility and adaptability in Fig. 4. The six edges represent the design conditions for eco-efficiency and eco-effectiveness in material and energy flows. This design methodology provides a framework to develop sustainable production systems.

The dynamics of cooperation, competition and coopetition shape the relationship between VCMs, production systems and ecosystem. To stimulate a win-win-situation for all stakeholders in the value creation network, their preferences must be reviewed under local, regional, national and international limitations. To indicate economic, environmental and social effects, a model for production systems considering preferences and limitations is presented. Preferences for a production system consist of company goals within the limitations of the ecosystem. The next step is to apply the proposed design methodology and to devise technological solutions, which will increase the local added value for agricultural production in Cyprus. The inductive path provides descriptive values and on field measurements to close the iterative design loop and continuously improve the design methodology.

\section{Increase of local added value in Cyprus}

In order to design sustainable production systems, engineers must be educated to understand the economic, environmental and social effects of value creation within local and global limitations. When the necessity of sustainable development is understood, the next step is to analyze and design value creation at every stage of development.

This section presents the results of an international project established by the Berlin Institute of Technology (TU Berlin). TU Berlin, a pioneer in its field, has been launching outcome oriented engineering courses with international industrial and educational partners since 1998. These courses stimulate the multilevel transition of engineering capabilities: students learn simple knowledge reproduction, which is named "learning"; then they learn how to understand the patterns between value creation and consequences by "thinking"; later they train to develop sustainable solutions, which is named "creating" (Seliger 2011). Following the "Learning by Doing" principle, the creative inductive process of devising technological solutions represents both merging action and the experience of engineers with project orientation. Projects address existing industrial issues of how to shape value creation via scientific approaches. To address existing industrial issues, Global Engineering Teams (GET) are established with students of (Oladiran et al. 2011) universities in South Africa, Botswana, Chile, USA, Brazil, South Korea and Germany (Seliger et al. 2004). The Middle East Technical University (METU) in North Cyprus is involved within this network, having served as a forum for international research on sustainable manufacturing since 2012 .

The international project team involves fourteen graduate students from the departments of production technology, industrial engineering, mechanical engineering, sustainable environment, renewable energy studies, information technologies; it is made up of six Germans, three Cypriots, two Turks, one Spaniard and one Indian student, five scientists from METU, two researchers from TU Berlin, around thirty governmental institutions and companies from the agricultural, water and energy sectors in Cyprus (Emec et al. 2013). 
The aims of this project are (1) to train engineers in critical thinking through combining technological solutions by addressing key requirements of sustainable development; (2) to create empathy for regional conditions and limitations; (3) to raise awareness for synergies and tradeoffs in production systems; (4) to promote innovation and entrepreneurship; and (5) to demonstrate developed applications and their competitive advantages.

The task of the project team is to find a sustainable technological solution. By applying the developed design concept, the solution should increase the local production depth of a crisis-ridden region in southern Europe. To exacerbate this duty, a region in Cyprus limited by trade barriers and affected by climate change is selected as the implementation area.

The first step is to model the industry in North Cyprus according to the referred value creation architecture. The second step is to determine high value adding production systems and processes by carrying out strengths, weaknesses, opportunities and threats (SWOT) analysis. After identifying preferences, limitations and establishing their current position in global markets, the eco-efficiency and eco-effectiveness of local processes are analyzed. The seasonal availability of renewable resources and geo-political limitations will be overcome with technological solutions. The third step is the provision of technological solutions for value creation modules to increase local added value by fulfilling design conditions of changeability, eco-efficiency and eco-effectiveness. The developed production system enables decentralized agricultural production following the principle "local for local" in a sustainable manner.

\section{Limitations of ecosystems}

In the twentieth century, Cypriot youth continued higher education mostly in Commonwealth countries founded by the British Empire. The entrepreneurial spirit was not supported and, after graduation, most youths became public officers on the island. The civil war in Cyprus has caused a generation with mental diseases which could not identify private and commercial targets. Their ethical values are oriented at family and supported by governmental subsidies, but these values do not focus on sustainable development. The impact of climate changes on agricultural production, such as weaknesses in value creation and the decreasing availability of energy and fresh water, are no longer an issue confined to underprivileged and rural areas. For developed countries in southern Europe, for example, the increasing frequency of natural disasters heavily impacts agricultural production through damage to property and infrastructure, which leads to lost productivity or inefficiency (Iglesias et al. 2007). The awareness of and forecasts for future limitations triggered by changed dynamics of the ecosystem require a paradigm shift in traditional food industries (WWAP 2014). In the last decades, this situation led to a corrupt economy in Cyprus, which threatens the interdependency of the island. To overcome the distressed situation, conversion of these threats, into opportunities for Cypriot entrepreneurs is needed.

According to the design methodology, flexibility and adaptability combined with eco-efficient and eco-effective agricultural production systems can provide better food and increase the local competitiveness of farmers. Through technological and managerial competencies, the challenge to fulfill modern society's needs must be continuously understood and acted upon. Limitations of ecosystems and regional applicability of design conditions are defined as constraints. Technological solutions must be developed, assessed, implemented and continuously improved to adapt to changing constraints. As semi-closed ecosystems, islands in southern Europe are significantly affected by climate change. Considering the restrictions imposed by trade barriers in addition, shows that the entrepreneurial freedom of action in Cyprus is extremely limited. To overcome regional limitations and constraints, Cypriot production systems must change.

Preferences for planted harvest goods and the availability of resources for regional production are analyzed in order to determine both limitations and the current position of Cypriot agriculture in global markets. The data is mainly provided from the Ministry of Agriculture and Natural Resources Statistics in the Turkish Republic of North Cyprus (TRNC), from the Planning Division of the Department of Meteorology in the Republic of Cyprus (Department of Meteorology, Republic of Cyprus 2012) and from the European Climate Change, Hydro-conflicts and Human Security Report (Bruggeman et al. 2012).

Currently, the production of agricultural goods in North Cyprus is hampered by rising energy prices and scarce water resources. The sinking groundwater level from a depth of 40 meters to a depth of 100 meters and increased salinity during summer time are two of the main effects of climate change. These changes trigger regulatory and economic counteractions, e.g., rising fuel costs for pumping ground water for irrigation and investment in new, deeper wells, including new filter technologies. These constraints increase the local production costs for agricultural goods and decrease the competitive advantage of regional goods on global markets. The results are higher $\mathrm{CO}_{2}$ emissions per product, lower local added value, and increased unemployment.

In the last decade, electricity prices for industry in North Cyprus have increased over $250 \%$ and annual consumer prices for fuel have increased over $300 \%$. Increased prices 
Fig. 5 Annual precipitation of Cyprus of the last century (Bruggeman et al. 2012)

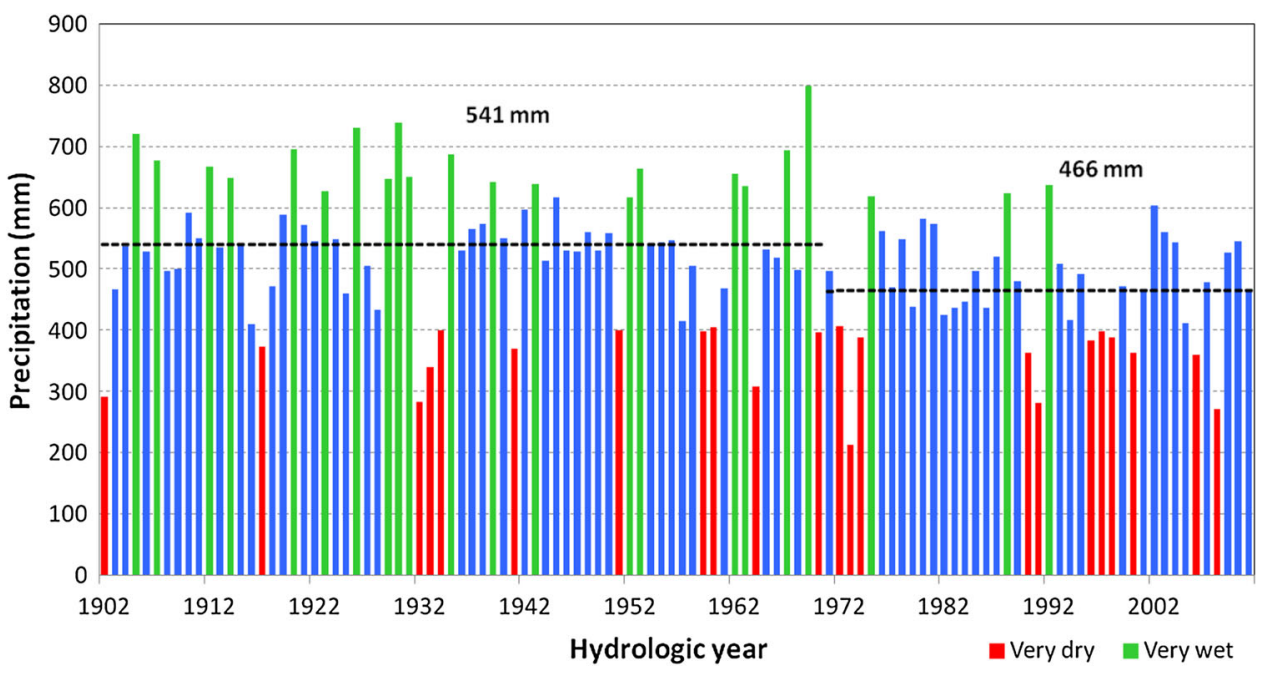

directly affect farmers, because diesel generators operate water pump systems for irrigating plants over a 5-month dry period in summer. On the other hand, Cyprus has a huge potential for solar energy, with a substantial 326 days of sunlight. In summer, the daily solar irradiance is about $7 \mathrm{kWh} / \mathrm{m}^{2}$, which is as high as locations near the equator. In the winter, the daily solar irradiance lies at $3 \mathrm{kWh} / \mathrm{m}^{2}$, which is as much as the daily average solar irradiance for Germany over an entire year. Wind energy is not directly accessible on the island, although mountain or coastal areas have potential for wind energy. Lack of comprehensive measurements hinders wind potential analysis. The average wind speed in Cyprus is $3.3 \mathrm{~m} / \mathrm{s}$ and lower compared to Hamburg, Germany with, e.g., $4.35 \mathrm{~m} / \mathrm{s}$. The wind speed variation for the coastal region over a day in, e.g., in South Cyprus, is on average $2.5-6.3 \mathrm{~m} / \mathrm{s}$ (TRNC Ministry of Agriculture and Natural Resources 2011).

The average annual precipitation between 1970 to 2010 in Cyprus was $466 \mathrm{~mm}$, as compared to $541 \mathrm{~mm}$ between 1901 to 1969 (Department of Meteorology, Republic of Cyprus 2012). As presented in Fig. 5, very dry periods rarely occur. During the last two decades, the average annual precipitation decreased to $461 \mathrm{~mm}$. However, while the average annual precipitation over the last 3 decades is stable, the yearly rain period has been shrinking from 4-5 months to 2-3 months. This brings regional floods more often and causes an insufficient regeneration of the ground water level (Bruggeman et al. 2012).

Additionally, since the 1960s, over 80 dams with water capacity for more than 300 million $\mathrm{m}^{3}$ have been built in South Cyprus. Dams are partly recharged with ground water and also impact the sinking ground water levels in North Cyprus. This causes a strong deterioration of the water situation in North Cyprus, which now has a capacity for less than 20 million $\mathrm{m}^{3}$ annually.
To reduce the social impact of this water problem, the Cyprus Water Supply Project was started in 2011, at a cost of approximately 320 million Euros. The main stakeholder of this international water diversion project is the Republic of Turkey. The project is designed to supply water from South Turkey to North Cyprus via a pipeline of 22,000 m length for a time span of 50 years. It will carry 75 million $\mathrm{m}^{3}$ water at a $250 \mathrm{~m}$ depth under the Mediterranean Sea. The main purpose of this project is to supply water for drinking and irrigation in North Cyprus (Gies 2013). The government from North Cyprus and Turkey have selected some areas to install special pipelines for irrigation. It is still unclear how many and which Cypriot farmers will draw benefits from this project.

The existing agricultural goods of North Cyprus provide an overview of the beneficial products and production steps for more local added value. The major agricultural products are almonds, olives, pomegranate, and citrus fruits. The average harvest in North Cyprus between 2006 and 2010 was about 600 tons/year of nuts, 4000 tons/year of olives, 800 tons/year of pomegranates and 150,000 tons/ year of citrus fruits (TRNC Ministry of Agriculture and Natural Resources 2011). Citrus fruits are not regional Cypriot crops. They were imported and cultivated under the British Empire at the beginning of the nineteenth century to meet the demands in Great Britain. The water demand of citrus trees is ten times more than that of olive or almond trees.

However, the harvest amounts do not indicate the real potential of these goods. Harvested goods can be processed as different value added agricultural products in order to make more profit from the biological harvest. The higher the value added through processing, the higher the market price. The pomegranate fruit sold in north Europe in 2014 for around $2.00 € / \mathrm{kg}$, the peeled pomegranate seeds are 
Fig. 6 Design of agricultural production system (APS)

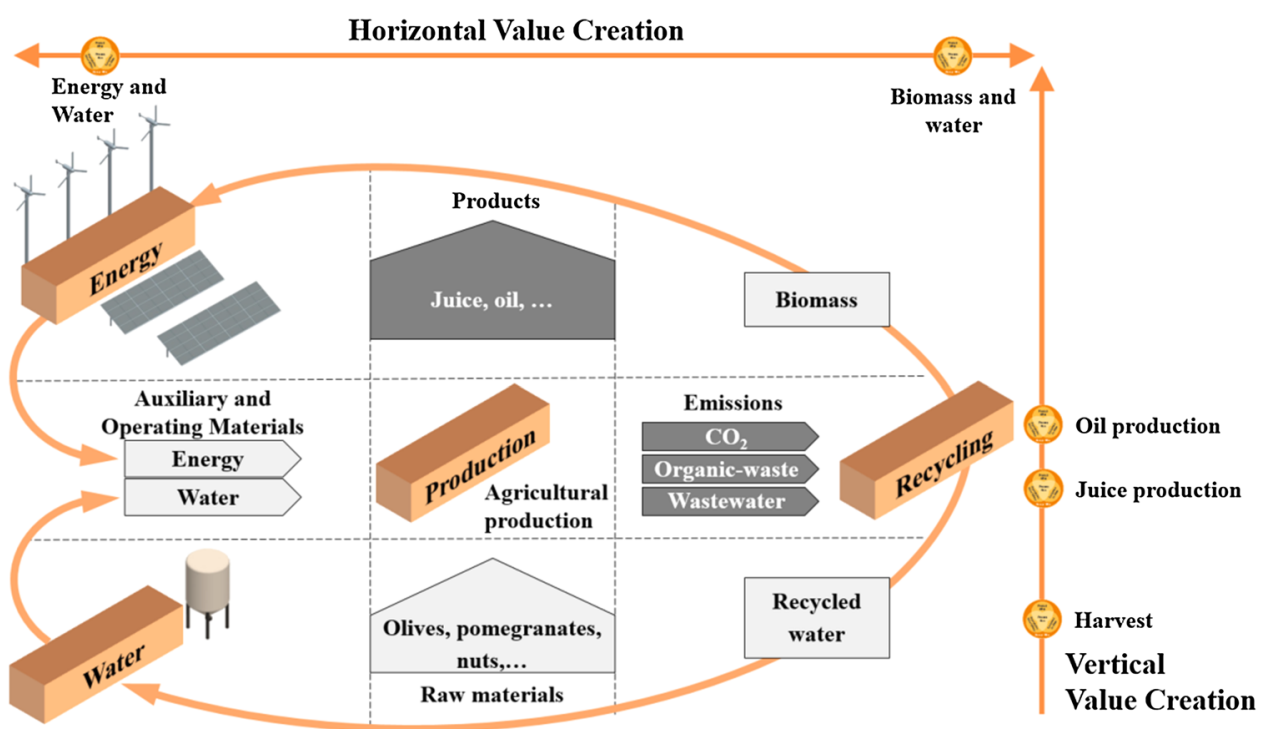

sold for $4.00 € / \mathrm{kg}$, and its juice sells for $6.00 € / \mathrm{kg}$. Pomegranate syrup sells for $50.00 € / \mathrm{kg}$ and pomegranate oil for $200 € / \mathrm{kg}$. Furthermore, each pomegranate product from North Cyprus could be sold with a certificate of $\mathrm{CO} 2$ neutral production estimated for $5 \%$ higher market prices, and, with a fair-trade and organic certificate, which results in $20 \%$ higher prices.

The analysis of limitations in North Cyprus indicates the inextricable link between the water and energy demands of regional agricultural production systems. To increase competitiveness and local production depth, auxiliary and operating materials such as water and energy need to be generated sustainably. Oil production from crops is proposed from a previous analysis as the process with the highest local added value. The next section presents the design methodology for a sustainable agricultural production system (APS) considering constraints in Cyprus.

\section{Design of production systems}

Design is the creation or shape of an object which increases its value. There are two basic design models which are discussed in "The Rational Model," developed from Pahl and Beitz, and in "Evolutionary Design," described by Brah and Maimon (Pahl et al. 2007). The rational model represents the inductive process of creation and posits that design processes attempt to optimize the object under known constraints and objectives; it is plan-driven and understood in terms of a discrete sequence of stages. The main critique of the rational model is that goals are often unknown when a design process begins, and the requirements and constraints continue to change. The evolutionary design concept, also called the "design cycle," describes the reflective and repetitive structure of a design process that represents the deductive process of creation. The design cycle is understood as a circular time structure, which starts with the thinking process of an idea, then expressing the idea, sharing and perceiving the expressed idea, and finally starting a new cycle with the critical rethinking of the perceived idea. The assumption is that the structure of the design process is reflective and repetitive. Reflection can be reached by visualization tools to start a new cycle with the critical ranking of the shaped object. The critical ranking should be based on attributes determined from key requirements and observed stakeholder preferences. Continued improvement of the design methodology can be ensured by closing the loop from deductive thinking process to inductive observing. The proposed design methodology combines both approaches into one in this paper. Based on the observation of regional limitations and interviews with Cypriot stakeholders, five design preferences were established: (1) decrease energy costs; (2) increase accessibility to clean water; (3) increase local production depth; (4) increase eco-efficiency and ecoeffectiveness; (5) increase the overall benefit of the production system.

To satisfy changing constraints, modular designed production systems are independently developed and implemented as previously identified sub-classes in "locally for local" structure. As presented in Fig. 6, the production system is divided into independent value creation modules in separate containers following the principle of mini-factories. All value creation modules of the production system have the standard design of shipping containers of 6-16 m, as established by the International Organization for Standardization (ISO-Norm 668). Each container can be defined as a mini-factory because all the equipment required for a certain product is included in that container. 
The decentralized system targets local production planning and operating close to the harvest area. This decentralized production saves time and transportation costs.

The modular design of the production system allows more changeability: (1) the energy module continuously generates the required energy from renewable resources and organic waste. It produces lower energy expenses for the whole system, increases eco-effectiveness and decreases $\mathrm{CO}_{2}$ emissions; (2) the water module applies atmospheric water generation consequently independent of ground water; (3) through the mobile postharvest production module, farmers gain better and faster access to facilities for processing their harvest. This increases ecoefficiency by reducing transport costs, and $\mathrm{CO}_{2}$ emissions, and increases the quality of olive oil by shortening the time span between harvest and production. (4) The attached recycling module adds value through the recycling of organic waste and wastewater in order to reuse byproducts; it also increases eco-effectiveness by generating, for example, thermal energy from biomass.

The preferences for agricultural production systems based on environmental limitations are presented. To increase the flexibility and adaptability of agricultural production systems, a modular design concept is developed. To meet the requirements for eco-efficiency and ecoeffectiveness, "local for local" mini-factories are selected and implemented. The next step is to discuss the technological solutions for each module and demonstrate how to increase the overall benefit by applying product-service systems.

\section{Technological solutions}

Technology is the art of value creation. In Greek, the word 'art' includes any process for the production of an object.
Art is creative expression, it presents solutions and reflects the mental state, feelings, ideas, sense or vision of humankind. Creativity is the action of continuously creating something new and detectable. By using tools, design facilitates growing consciousness through the manifestation of solutions. Robert L. Peters summarizes the relation between these concepts as "Design creates culture. Culture shapes values. Values determine the future."

This section describes the technological solutions for value creation modules, which increase local added value by fulfilling design conditions, and evaluate various business approaches by considering socio-eco-effectiveness.

The proposed production system, including material and energy flows, is presented in Fig. 7. The production module is the central asset of the system. Energy and water are created as needed in the production module by the respective modules. Following traditional methods, olives are pressed, centrifuged, and filtered in olive mills for the extraction of their oil. The remaining paste contains a small quantity of around 5-10\% of oil that cannot be extracted by further processing without the use of chemical solvents. This remaining paste is an input for the recycling and energy modules as biomass. 150,000 tons of agricultural products can be processed annually, with a corresponding dried waste of up to 15,000 tons biomass annually. Multiplying the available amounts of biomass with the specific heat rates gives an equivalent thermal energy of $3.5 \mathrm{GWh} /$ month or about $45 \mathrm{GWh} /$ year. In terms of electrical energy, it returns $18 \mathrm{GWh}$ if one assumes an efficiency of $40 \%$.

The bio-waste is dispatched to the recycling module, and converted into pellets for later use, e.g., in the energy module. The wastewater produced from cleaning the olives and from the secondary centrifugation of olive oil is redirected back to the water recycling module for purification.



Fig. 7 Agricultural production system (APS) including material and energy flows 
The energy module supplies the entire system, including the water and recycling modules, with electrical energy and if needed with process heat. To filter the pressed oil from residues in agricultural production, three water treatment technologies have been analyzed for the recycling module: both electrocoagulation technology and upflow anaerobic sludge blanket (UASB) technology are used for the pretreatment of the liquid residues (UP ZRS 2009). Centrifuging Ultrafiltration Reverse Osmosis (CURO) presents another possibility to clean the production residues. The index to measure the quality of the wastewater is known as the removal efficiency of biological oxygen demand. The removal efficiency varies from $50 \%$ by electrocoagulation, over $70 \%$ by UASB, and up to $95 \%$ by CURO.

The resources which ensure the generation of electricity in the energy module must meet the following local constraints: independence of location, availability of energy resources, required space, and affordable price, as well as creating fewer $\mathrm{CO}_{2}$ emissions, in contrast to currently used solutions. In order to provide the required energy, the module consists of two parts, clean energy and backup: The purchased hybrid energy system generates clean energy from the input of solar radiation, wind and biomass. It is also complemented with a diesel generator and storage batteries as backup. Alternative combinations of renewable energy resources are specifically created and assessed. The energy module encompasses available renewable resources in different combinations that are aligned with the energy demands of the three other value creation modules in Fig. 6: the production module, the atmospheric water generation unit taken as water module, and the water and biomass recycling unit as recycling module. The hybrid energy module increases the availability of the energy supply with less operating expenses and less $\mathrm{CO} 2$ emissions. The return on investment for the energy module is between 4 and 6 years depending on configuration and capacity.

The water module provides an uninterrupted supply of water to the production module in a sustainable way. Atmospheric air is the input for water generation. Different techniques are examined to meet this demand, such as condensation, filtration, and the conveyance of water from its source to the point of usage. The selected technique is based on criteria such as mobile access, the lowest possible energy consumption, and availability. This also includes the energy consumed for transporting the equipment.

However, filtration and osmosis rank low, because otherwise the module would need to be located close to the coast, which contradicts the requirement of mobility. The conveyance of water requires drilling holes into the ground, considering the availability of usable ground. Because of increased salinity over the summer, additional filtration systems are needed. Condensation is the only technique which matched all the criteria. The available technology is atmospheric water generators. This technique was developed by engineers using biotical creativity methods during their study on the water balance of beetles living in deserts. The observed process begins when heat is radiated from the matte black exoskeleton, resulting in a body temperature slightly lower than that of the surrounding air. The moist breeze comes into contact with the cool exoskeleton and water condenses into small drops and rolls down to be trapped in the beetle's mouthpart.

The proposed water generation succeeds through a device extracting water from humid ambient air, which mainly consumes energy to run the compressor for the heat exchanger and fan unit. Alternative solutions like the wind-water turbine incorporate the working principles of a

Table 1 Specification of local value creation for agricultural production in Cyprus

\begin{tabular}{|c|c|c|c|c|c|}
\hline \multirow{2}{*}{$\begin{array}{l}\text { Value } \\
\text { creation } \\
\text { module } \\
\text { (VCM) }\end{array}$} & \multicolumn{5}{|c|}{ Value creation factor (VCF) } \\
\hline & Product & Process & Equipment & Organization & Human \\
\hline Energy & $\begin{array}{l}\text { Electrical } \\
\text { energy and } \\
\text { heat }\end{array}$ & $\begin{array}{l}\text { Photoelectric effect, } \\
\text { electromagnetic } \\
\text { induction and } \\
\text { combustion and storing }\end{array}$ & $\begin{array}{l}\text { Solar panels, wind turbine, } \\
\text { generator, battery and } \\
\text { combustion chamber }\end{array}$ & $\begin{array}{l}\text { Daily production planning, } \\
\text { configuration of energy mix, } \\
\text { distribution and storage depending } \\
\text { on demand }\end{array}$ & $\begin{array}{l}\text { Operator and } \\
\text { distributor }\end{array}$ \\
\hline Water & Water & Condensation & $\begin{array}{l}\text { Cooling compressor, heat } \\
\text { exchanger, humidity } \\
\text { condenser, fan and water } \\
\text { tank }\end{array}$ & $\begin{array}{l}\text { Daily production planning and } \\
\text { distribution depending on demand }\end{array}$ & $\begin{array}{l}\text { Operator and } \\
\text { Farmer }\end{array}$ \\
\hline Production & $\begin{array}{l}\text { Olive oil or } \\
\text { pomegranate } \\
\text { juice }\end{array}$ & $\begin{array}{l}\text { cleaning, separation, press } \\
\text { and packaging }\end{array}$ & $\begin{array}{l}\text { Mill, malaxer, decanter and } \\
\text { separator }\end{array}$ & $\begin{array}{l}\text { Seasonal production planning } \\
\text { depending on harvest }\end{array}$ & $\begin{array}{l}\text { Farmer and } \\
\text { production } \\
\text { planner }\end{array}$ \\
\hline Recycling & $\begin{array}{l}\text { Solid waste in } \\
\text { pellets, water } \\
\text { and fertilizer }\end{array}$ & $\begin{array}{l}\text { Drying, pressing, } \\
\text { centrifuging and } \\
\text { ultrafiltration }\end{array}$ & $\begin{array}{l}\text { Belt dryer, pelleting press, } \\
\text { separator, and nano- } \\
\text { filtration }\end{array}$ & $\begin{array}{l}\text { Seasonal production planning } \\
\text { synchronized with production }\end{array}$ & Operator \\
\hline
\end{tabular}


wind turbine and an atmospheric water generator, so that they can produce water as well as electricity. Electricity is produced by the action of turbine blades in a conventional wind turbine (eolewater 2010).

Figure 2 presents the summary of services which can be provided with such a production system. The production service systems are adapted to the business ecosystem of North Cyprus. Each VCM provides a service representing the value creation factor $(V C F=$ product $)$. This concept is designed to provide electricity from renewables, water from air, and to enable processing of local goods, e.g., olive oil. The names of the VCMs define the technological processes of water and energy generation, crops processing, and recycling $(V C F=$ process $)$. The modules, including the equipment, enable mobile and modular processing $(V C F=$ equipment). The business module is presented through organization of a product-service system (PSS, $V C F=$ organization) approach. The stakeholders in this case are farmers, operators and entrepreneurs, as well as engineers $(V C F=$ human $)$.

The local APS in Cyprus is specified, with its factors, for each VCM. Table 1 presents the most relevant factor specifications for each module except for the business module. Due to its intermodal functionality, the business module, hereafter referred to as business approach, integrates all other modules into a production system.

To implement the container solution in Cyprus effectively and ensure its competitiveness in international markets, a business model integrating multiple stakeholders is needed. Based on case-specific assumptions, two alternative models are developed: (1) providing all four modules in a container as a production system is called a stand-alone (SA) product. (2) Providing the functionality of the production system with four modules is called a Product-Service System (PSS).

An online platform for stakeholders is established and functions as cloud services. The cloud enables easy access to services via mobile phones, thus reducing hardware costs. Services include for example booking the container, scheduling for the farmers, and higher production capacity utilization according to the seasonal needs of farmers. The continuing education of stakeholders via cloud services shortens the response time to changing regional limitations and global markets. The mobile APS can be accessed by every farmer and market actor. Both only need to pay for the functionality. APSS also supports the creation of more added value, and enables the increase of eco-efficiency and eco-effectiveness by decentralized and easy access, for example through an application (APP) for mobile devices such as smartphones and tablets (Emec et al. 2013):

(3a) An APP-Harvest organizer displays the availability of production time, cost, and capacity on an online calendar and provides a seamless reservation function. An exchange market represents a platform for farmers to offer their labor in order to help each other with the harvest. This APP increases socio-eco-effectiveness because it is marked by farmers' willingness to cooperate, exchange knowledge, and trust each other. Eco-efficiency increases because of shared manpower and equipment in situations such as sequentially collecting the harvest. The more farmers, the more sequential harvest is possible, and the better the production schedule. Sequential harvest can increase the efficiency of scheduling and the quality of the oil, because of the low storage time of olives. (3b) An APP-market data provides real-time information about meteorological conditions, and the market prices, availability of solar and wind energy, as well as a forecast of $\mathrm{CO}_{2}$ emissions per liter of produced oil or juice. (3c) An APP-training tutorials provide information on how to produce organic food, and how to harvest and increase the quality of fruits. Farmers can be updated about new technologies and innovation in agricultural production through new scientific studies, and they can discuss the findings interactively. (3d) An APPpersonalized interface provides farmers with a profile page, also called "quality face," for marketing and information exchange purposes. Each farmer can share his certificates and awards on his page. The online platform has a messenger function, which can be used by farmers to review their interactions with other farmers, to give feedback and establish a trust rating. (3e) An APP-customer opens an online showroom to global markets. Enabling direct transactions between farmer and customer saves retailer prices, increases the profit of farmers and the trust in organic food production, and contributes to building longterm direct relationships between customers and farmers.

Developed APPs can support stakeholders who are using PSS in improving their economic impact by saving energy, water and processing costs for stakeholders; their environmental impact by decreasing $\mathrm{CO}_{2}$ emissions, and their social benefit through diverse cooperation between farmers, entrepreneurs, and customers. The presented technological solution allows sustainable production and enables coopetition between stakeholders by sharing production systems. The next chapter presents the assessment of the fulfillment of key requirements.

\section{Assessment of methodology}

In order to assess the fulfillment of key requirements by technological solutions, we define attributes, which indicate either the current position or the direction and rate of change toward a particular goal. The aim of the presented case study is to close the inductive creative design loop and identify synergies within the Cypriot ecosystem in order to improve added value. Global challenges and local 
limitations are analyzed according to Geddes' concept. This analysis shifted the focus to agricultural production. An annual production period of six months is analyzed; each month contains thirty days, each day contains two shifts, and each shift covers seven working hours. There is no processing of agricultural goods in the other 6 months, but energy and water generation still take place. The results show that on an hourly basis, $200 \mathrm{~kg}$ of olives are processed into $50 \mathrm{~kg}$ of olive oil, which are sold (with $100 \%$ sales success) at a retail price of $2.5 € / \mathrm{kg}$. For a production capacity of 3 tons of olives per day, the simulation shows maximum energy consumptions for the water module of $3.9 \mathrm{~kW}$, for the production module of $4.6 \mathrm{~kW}$ and for the recycling module of $3.8 \mathrm{~kW}$.

Unfortunately, both states on the island, the Turkish Republic of North Cyprus and the Republic of Cyprus, as well as international institutions, restrict access to public data. There are significant variations among data from different investigators, for example, about gas discoveries in the northern and eastern basin of the Mediterranean Sea. The lack of standardization in environmental data management and the poor resolution of measured data made it necessary to carry out a detailed survey with stakeholders. The identified stakeholders are farmers who harvest olives, pomegranates and nuts; mill owners; operators of juice presses; public officers from governmental institutions (such as ministries for agriculture, natural resources, economy, energy); ministers from research institutes and laboratories; pump and generator, and nongovernmental organizations (such as wind energy system providers and the heads of agricultural producers' unions).

Easy access to production assets, such as olive presses, is the primary means by which farmers gain a competitive advantage. The shorter the time between harvest and pressing, the higher the quality of olive oil. Use of regional, low priced energy and water supplies, as well as access to water over dry seasons, will further increase competitiveness. The demand is proportional to both harvest quantity and the duration of individual processes. The challenge is to model a simulation of real demand with variable input loads and the dynamic availability of renewables. Existing assessment tools support decision-making for production systems including either effects for competitiveness or for sustainability as presented above. However, a multi-perspective view on technological solutions is needed for assessment in order to select the best fitting solution among the given alternatives. An assessment approach is developed to support the decision-makers following the multi-attribute utility analysis.

The first question in the assessment is whether the proposed technological solutions are effective, i.e., if the right value is created. This question cannot be answered entirely because of unknown factors in any assessment procedure. To increase the quality of the results, an assessment must consider multiple perspectives and determine all impacts and relations triggered by the value creation activities. This procedure correlates with the availability of knowledge and awareness of the current production and ecosystem. All production systems are affected by unknown factors, which could lead to creating a better value. A deductive process is applied in order to overcome the lack of information. The functional needs of stakeholders are identified and integrated into the assessment procedure. Validation intends to select the technological solution for each VCM that meets the key requirements better than other solutions. The overall goal for sustainable development is translated into attributes based on the key requirements according to the Balanced Scorecard. Attributes attach a value to solutions regarding stakeholder preferences. Technological solutions with the highest value for each VCM are used to configure the APS.

The second assessment question to confirm the selection is whether the APS operates efficiently, i.e., if the right creation for the value is performed. Technological solutions must overcome at least one limitation efficiently without compromising the sustainability of the whole system. The APS is verified through variations which are representative for slight changes in technological solutions.

The aim of the next step, the simulation, is to check if the APS overcomes the local limitations. A set of measurements are identified in order to characterize the degree to which design conditions are fulfilled. These values determine the economic, environmental and social effects according to life-cycle analysis. The assessment approach composed of validation and verification is described in the following sections.

\section{Validation}

The following attributes are identified and examined in order to compare technological solutions: (1) educational capability: how capable is the APS to create awareness for sustainable manufacturing? This is assessed through the degree of assurance that a technological solution can create awareness for farmers, who can learn from the experience with the APS and improve the overall value creation. (2) Functionality: when sustainable development must ensure business success, how successfully does each solution satisfy functional needs? Functionality can be assessed by considering farmers' needs as well as predetermined design conditions. An increase in productivity and a decrease in investment costs for farmers indicate higher values. (3) Stakeholder empowerment: how far is the entrepreneurial spirit of stakeholders stimulated beyond involvement in value creation? The degree of empowerment can be estimated by the existence and extension of win-win- 
Table 2 Assessment of agricultural production system



situations; increased freedom of action; social well-being and direct contact to customers worldwide. (4) Eco-effectiveness: when overall goals must be continuously reviewed in order to improve value creation, how eco-effective is a technological solution with regard to these goals? This effectiveness can be assessed through the degree of no longer disposed and non-renewables substituted by renewables. (5) Eco-efficiency: when less resources, higher speed and less waste save money, time and resourcesincluding raw, auxiliary and operating materials-how eco-efficient is the resulting value creation? Eco-efficiency can be assessed by considering the environmental impacts. (6) Service integrity: how much new added value can be created through selling a functionality? ICT-based services support generation, analysis and distribution of information. The services can be assessed through the increase in efficiency and added value. (7) Changeability: when VCMs must respond to changing constraints continuously, how adaptable and flexible are the presented solutions? As containers, VCMs can be easily transported to different harvest regions which enables a high mobility of the APS and indicates a superior flexibility of the solution.

The stakeholder preferences investigated in Cyprus provided the values of attributes for validation. Values indicate the quality of the technological solution; in other words, the extent to which the technological solution meets key requirements according to stakeholder preferences. The higher the quality is, the higher the need to implement the respective solution. The higher the quality is, the higher the need to implement the respective solution is. Three values are determined based on the overall goal of sustainable development in Table 2, to which a technological solution is deemed adequate for an attribute. The value of an attribute is (1) high, if a technological solution improves economic, environmental and social effects, which indicates that all required conditions are met; (2) middle, if a solution overcomes at least one limitation without compromising sustainable development; (3) low, if a solution improves only single impacts, and it adversely affects sustainable development. 
For example the goal of the energy module (VCM) is to generate electrical energy. Energy generation is rated positively if little or no carbon-dioxide is emitted. Using biomass, solar, wind, or hybrid energy sources in order to generate electricity for the power grid increases eco-effectiveness. To ensure the continuous availability of electricity by exploiting seasonally and climatically available renewables, a hybrid energy generator is the best fitting and most adaptable solution.

Seasonal water scarcity represents a major limitation in Cyprus. The reason is that pumped groundwater exceeds the natural regeneration of water reservoirs and has a negative impact on the ecosystem. Additionally, facilities for filtration and conveyance are not fulfilling the changeability condition of mobility. Also, investment and running costs for these facilities are high. Technologies for condensation require a high investment sum, but have low running costs and also represent an eco-effective technology with an unlimited capacity to extract water from atmospheric air. Unlimited water extraction in Cyprus is possible, because of the average temperature over the period of a year-between $10^{\circ} \mathrm{C}$ to $26^{\circ} \mathrm{C}$ - and an average humidity of $30 \%$ to $70 \%$. The principle of condensation is flexibly applicable for a changing demand.

A production module is classified according to the geographic distribution of facilities into: (a) centralized, e.g., to press orange or pomegranate juice and (b) decentralized, e.g., to press olive or nut oil. To guarantee a high quality for the olive oil it is necessary to process the harvested goods within $24 \mathrm{~h}$. A well-coordinated schedule and scalable production capacity is also crucial. Modular and mobile APS would be a well-fitting solution to attain this production goal.

The recycling module aims to reuse solid and liquid residues, increasing overall eco-effectiveness. Wastewater can be treated in order to be reused in the production module and dry bio-waste can be pressed into pellets to generate electrical and thermal energy. Transforming solid residues into pellets and fertilizer generates more output per time with less investments costs, is easy to operate, and requires little space and mid-level know-how. The technology for pellets, therefore adds more value than the water treatment methods previously presented.

The APS can operate as a stand-alone or as a shared unit. This allows for maximum entrepreneurial freedom for the owner of the APS, as the services to generate energy and water, to process goods, and to recycle emissions can be offered separately. The awareness-raising and learning outcomes for the owner are high; so are the investment costs.

The functionality of the APS with all VCMs and cloud services, also called PSS, provides energy and water, and ensures production when, where, and however much is needed. The sharing of the APS by multiple users enables a mini-factory, composed of four containers at a preselected location. Surrounding farmers can process their harvest and supply water for irrigation in a closed-loop through energy generation and the recycling of waste. In particular, APS sharing increases facility utilization and resource productivity. What is more, interactions between farmers and APS operators open space for further innovation.

ICT is the main driver for innovation. Conventional control units can regulate and monitor processes, resource consumption and time schedules. These ensure compliance with predefined goals for a single piece of equipment by continuously monitoring sensors' values. To create sustainable added value beyond conventional control units, new services are provided through extended applications (APP) and easily accessible interfaces for all stakeholders. The services created by ICT include the organization of seasonal harvest for each farmer, booking the container, sharing market data, creating advertisements, providing trainings and a personalized marketing platform. Combined with user interfaces through cloud services, apps enable visibility and networking, as well as continuously reviewing the APS. Apps provide high value by generating coopetition and win-win-situations for farmers. App services can also enable farmers to help one another with the harvest and share knowledge in order to increase both learning and teaching productivity in the Cypriot agricultural community. The limits of social compatibility are extended through sharing and saving manpower. Sharing the APS with higher sequential utilization increases socioeco-effectiveness. The training app attaches a high value to educational capability through the creation of awareness and provision of target oriented studies, current research results and online how-to courses.

Various technologies for each VCM are validated to compare the degree of attribute fulfillment. The VCMs with the highest values are combined with the APS which represents the most competitive and sustainable solution. In the next section, various configuration of the APS will be simulated to estimate the return of investment and provide recommendations for implementation.

\section{Verification}

Selected VCMs are combined to create more added value through synergies. The creative inductive process is adopted for the simulation of the physical transformations involved in the APS. The input variables for the selected solutions, e.g., available solar radiation, are slightly changed to develop multiple APS configurations. Simulation is needed to analyze the output, e.g., generated electrical energy, water and olive oil, as well as to estimate the economic, environmental and social effects of the 
configurations on the ecosystem. Assessment tools such as BSC and LCA need to be based on simulation results. To simplify the simulation, one input variable is changed, while all other inputs of the VCM are fixed so that they do not impact the output.

Exemplary input variables are changed to verify the ecoefficiency and eco-effectiveness through variations of the energy module. The energy generated by solar radiation, wind and solid waste delivers the energy mix. Due to the seasonal availability of solid waste and solar radiation, the energy module also needs wind energy. The proportions of solar radiation and solid waste have been increased from zero to one hundred percent in ten steps to develop eleven variations. The statistical data for solar radiation and wind speed, as well as measurements for solid waste, are used to calculate the energy output for each variation. The simulation results indicated that the highest values for eco-efficiency and socio-eco-effectiveness, as well as lowest environmental impacts, are achieved, when the energy mix is made up of $50 \%$ solid waste, $40 \%$ photovoltaics and $10 \%$ wind energy. This energy mix provides $120 \mathrm{~kW}$ per hour and can work 24 hours a day to supply power by using only renewable resources. For further improvements of environmental impacts, the cumulative energy demand of an agricultural product should be monitored and optimized when the energy module is implemented prototypically.

The focus on eco-efficiency shows that energy and water modules cause zero emissions and byproducts, because they use renewable and unlimited resources. The production module applies efficient technologies. Its byproducts are further processed in the recycling module which also increases the eco-efficiency of the APS. After the physical transformation of materials some byproducts can be processed through 6Rs. However, current technologies do not enable a $100 \%$ processing of byproducts and some percentage of production and 6Rs remains as waste.

The investments costs for an APS start at roughly 800,000 EUR. Expenses include operating and maintenance costs of approximately $7 \%$ per year which will be distributed among multiple farmers. A cost analysis with the return on investment approach based on the simulation results determines that, after ten years, the investment for the APS produces a positive return to the investors and entrepreneurs.

Services are utilized by the business operation through a product-service system (PSS) and apps which share online information and resources such as equipment and workers for harvest. The modular designed mini-factories in containers provide a mobile and changeable APS to adapt quickly to changing preferences and limitations. Including multiple participants' preferences creates a disorder which increases both the entropy of the APS and the number of directions to change the APS. Farmers can discuss advantages, as well as disadvantages, of the changes online. Different perspectives on the same issue can widen the space for either effective or efficient solutions. An innovative consensus can be achieved, even if, in the short term, it is not the first preference of each participant. When single or multiple participants identify opportunities, these can be exploited to increase the socio-eco-effectiveness of the APS. Through common understanding and solution finding, threats posed by worsening limitations can be avoided.

The project team and Cypriot stakeholders are convinced that the proposed APS configuration increases local value added under current local limitations in a competitive and sustainable manner. The implementation of the selected configuration should be elaborated in a follow-up project. A business plan is required, which should be presented to potential financial stakeholders. The design methodology can be applied iteratively in order to improve the quality of results, e.g., for increasing eco-effectiveness of the production and recycling modules. Recommendations for the next steps are given in the next section.

\section{Conclusions}

This paper introduces a new design methodology for increasing the local production capacity and regional competitiveness for production systems. The implementation in a region in southern Europe, which is crisis-ridden, as well as affected by the climate change and trade barriers, demonstrates the superiority of the methodology. The key requirements for sustainability and a set of design conditions are integrated into the axiomatic design approach. These design conditions are classified into two groups: (1) from the network perspective for increasing the eco-efficiency and eco-effectiveness in material and energy flows for production systems; (2) from the perspective of value creation modules for increasing the flexibility and adaptability with appropriate adjustments to changing limitations.

The developed methodology is based on a cascading combination of creative deductive processes, which provides the universal key requirements and design conditions for sustainable development, and inductive processes which determine the local preferences and limitations. Due to the universality of this methodology, competitive technological solutions can be developed and implemented in other regions where entrepreneurs are also challenged by resource scarcity.

The creative process of devising a technological solution is extended to a deductive process which provides the universal key requirements and design conditions for 
sustainable development, and inductive process which determines the local preferences and limitations in the value creation architecture. In order to overcome regional limitations through developing sustainable solutions, the inductive perspective is established based on ongoing experiences from agricultural production systems, and it includes the preferences of twenty stakeholders from farmers to electricity authorities in Cyprus. The main driver for competitive advantage, for example, for farmers is easy access to production assets such as olive presses. The shorter the time between harvest and pressing, the higher the quality of olive oil is. The use of local low priced energy and water supply, as well as access to water over dry seasons, will significantly contribute to additional success.

Technological solutions are developed based on what is most abundant, e.g., mobile connectivity and scalability to comply with what is scarce. After observing the challenging situation in Cyprus, the project team proposes an agricultural production system connected to cloud technology. The cloud technology provides the right information at the right time, and shows decision-makers how the current situation of the production system can be improved in order to increase the output. This enables better schedule of production capacity and services via mobile phones and reduces hardware costs. Several services are developed, for example, the harvest organizer which displays the availability of production time, cost and capacity on an online calendar with a reservation function for value creation modules. Additionally, harvest organizer provides a platform for farmers to help each other with the harvest. Sharing manpower and equipment, as well as collecting the harvest in a more sequential manner, improves the production schedule and product quality. The trust of stakeholders shall be gained through use of transparent data monitoring and access to shared services through PSS. The win-win situations will ensure a long-term coopetition and socio-eco-effectiveness. A swift implementation of the proposed solution would significantly improve the situation in Cyprus.

In order to gain competitive advantage, several certificates can be issued, based on the monitored data. They can attest the achievements of the producers to confirm, for example, zero emissions, fair trade, high quality and organic farming. It might be useful to develop further services later in order to stimulate cooperation and coopetition between stakeholders. Methodologies of how to model, maintain, assess and optimize their interactions between stakeholders can also be explored further. The stakeholders of the case-study assumed that solar radiation would solve any resource scarcity in Cyprus. However, the results show that the energy water nexus enables the highest benefit and accessibility to resources. Stakeholders should be encouraged to follow the design methodology, develop entrepreneurial spirit and technological solutions, as well as adapt to changing limitations. Critical thinking across understanding the pattern between value creation and consequences to create sustainable solutions should be mastered especially by stakeholders who are decisionmakers and engineers. These skills need to be integrated into educational programs.

Acknowledgments The authors gratefully acknowledge the funding of this work by the German Research Foundation (DFG), Collaborative Research Center (CRC 1026) and the Middle East Technical University North Cyprus Campus, as well as the support of the Konrad Zuse Institute Berlin.

Open Access This article is distributed under the terms of the Creative Commons Attribution 4.0 International License (http://creativecommons.org/licenses/by/4.0/), which permits unrestricted use, distribution, and reproduction in any medium, provided you give appropriate credit to the original author(s) and the source, provide a link to the Creative Commons license, and indicate if changes were made.

\section{References}

Abele E, Meyer T, Näher U, Strube G, Sykes R (eds) (2008) Global production. A handbook for strategy and implementation. Springer, Berlin, Germany

Agudelo-Vera CM, Mels AR, Keesman KJ, Rijnaarts HH (2011) Resource management as a key factor for sustainable urban planning. J Environ Manag 92(10):2295-2303. doi:10.1016/j. jenvman.2011.05.016

Alcamo J, Märker M, Flörke M (2007) Future long-term changes in global water resources driven by socio-economic and climatic changes. Hydrol Sci J 52(2):247-275 (journal des sciences hydrologiques)

Alexopoulos K, Chryssolouris G (2014) Process. In: Laperrière L, Reinhart G (eds) CIRP encyclopedia of production engineering, 1st edn. Springer, Berlin, Germany, pp 973-975

Bilge P, Badurdeen F, Seliger G, Jawahir IS (2015) Conceptual modelling to improve sustainable value creation. International Journal of Strategic Engineering Asset Management-Special Issue on Sustainable Manufacturing: A Systems Perspective (in press)

Bilge P, Badurdeen F, Seliger G, Jawahir IS (2014) Model-based approach for assessing value creation to enhance sustainability in manufacturing. In: ElMaraghy $\mathrm{H}$ (ed) Variety management in manufacturing. Proceedings of the 47th CIRP conference on manufacturing systems, April 28th-30th, Ontario, Canada. Elsevier, Amsterdam, pp 106-111

Bleischwitz R, Hennicke P (2004) Eco-efficiency, regulation, and sustainable business. Towards a governance structure for sustainable development, ESRI studies series on the environmentEdward Elgar, Cheltenham, UK

Braungart M, McDonough W, Bollinger A (2007) Cradle-to-cradle design: creating healthy emissions - a strategy for eco-effective product and system design. J Clean Prod 15(13-14):1337-1348. doi:10.1016/j.jclepro.2006.08.003

Bruggeman A, Charalambous K, Lange MA, Hadjinicolaou P (2012) Cyprus hydro-security profile. CLICO. http://www.clico.org/ component/docman/doc_download/51-hydro-security-profilecyprus?Itemid=. Accessed 3 July 2014 
Brundtland GH (1987) Report of the world commission on environment and development. Our common future. Oxford University Press, Oxford, UK

Chandler AD (1990) Strategy and structure: chapters in the history of the industrial enterprise. MIT press, Cambridge, MA, USA

Christophe F, Coatanea E, Bernard A (2014) Conceptual Design. In: Laperrière L, Reinhart G (eds) CIRP encyclopedia of production engineering, 1st edn. Springer, Berlin, Germany, pp 275-281

CRC (2013) Workshop on applied research in cooperation with German-Turkish industry. http://www.sustainable-manufactur ing.net/documents/10180/48554/PM14_2013-TDU.pdf/5404af 39-94d4-4731-b6cf-1ad309c54f08. Accessed 30 May 2014

Department of Meteorology, Republic of Cyprus (2012) Cyprus meteorological service (CMS). http://www.moa.gov.cy/moa/ms/ ms.nsf/809673481e49e516c2256fe1003598b7/5f3904afa57836 cbc22576c80036b9d5/\$FILE/Kipros_Mesi_Etisia_Vroxoptosi_ 1901_2011_UK.pdf. Accessed 31 May 2014

DIN (2009) DIN EN ISO 14040 Environmental management-life cycle assessment-principles and framework

Duflou JR, Sutherland JW, Dornfeld D, Herrmann C, Jeswiet J, Kara S, Hauschild M, Kellens K (2012) Towards energy and resource efficient manufacturing: a processes and systems approach. CIRP Ann Manuf Technol 61(2):587-609

ElMaraghy H, Wiendahl H (2014) Changeable Manufacturing. In: Laperrière L, Reinhart G (eds) CIRP encyclopedia of production engineering, 1st edn. Springer, Berlin, Germany, pp 157-163

Emec S, Bilge P, Seliger G (2013) Hybrid system of energy production and water supply for sustainable processing of agricultural products. Case study of Northern Cyprus. In: Proceedings of the 3rd international congress on sustainability science \& engineering, August 11-15, Cincinnati, OH, USA

Eolewater (2010) Specification sheet. WMS 1000 wind turbine. http:// www.eolewater.com/gb/our-products/range.html. Accessed 16 May 2014

FAO (2011) Energy-smart food for people and climate at FAO: an overview. Food and Agriculture Organization of the United Nations (FAO), Rome, Italy

Gies E (2013) Northern Cyprus sees hope in water pipeline. The New York Times. http://www.nytimes.com/2013/04/04/world/europe/ northern-cyprus-sees-hope-in-water-pipeline.html?pagewanted= all\&_r=0. Accessed 31 May 2014

Graedel TE (1996) On the concept of industrial ecology. Annu Rev Energy Environ 21(1):69-98. doi:10.1146/annurev.energy.21.1. 69

Hauschild M (2014) Environmental impact assessment. In: Laperrière L, Reinhart G (eds) CIRP encyclopedia of production engineering, 1st edn. Springer, Berlin, Germany, pp 465-468

Iglesias A, Avis K, Benzie M, Fisher P, Harley M, Hodgson N, Horrocks L, Moneo M, Webb J (2007) Adaptation to climate change in the agricultural sector. Report to European Commission Directorate-General for Agriculture and Rural Development

Jawahir IS, Dillon OW (2007) Sustainable manufacturing processes: new challenges for developing predictive models and optimization techniques. Keynote paper presented in proceedings of first international conference on sustainable manufacturing, October 17-18, Montreal, Canada, pp 1-19

Jayal AD, Badurdeen F, Dillon OW, Jawahir IS (2010) Sustainable manufacturing: modeling and optimization challenges at the product, process and system levels. CIRP J Manuf Sci Technol 2(3):144-152. doi:10.1016/j.cirpj.2010.03.006

Johnson R (2008) Kant's Moral Philosophy. http://plato.stanford.edu/ entries/kant-moral/. Accessed 01 Jun 2014

Jovane F, Yoshikawa H, Alting L, Boër C, Westkamper E, Williams D, Tseng M, Seliger G, Paci A (2008) The incoming global technological and industrial revolution towards competitive sustainable manufacturing. CIRP Ann Manuf Technol 57(2):641-659. doi:10.1016/j.cirp.2008.09.010

Mourtzis D, Doukas M, Psarommatis F (2012) A multi-criteria evaluation of centralized and decentralized production networks in a highly customer-driven environment. CIRP Ann Manuf Technol 61(1):427-430

Oladiran MT, Uziak J, Eisenberg M, Scheffer C (2011) Global engineering teams-a programme promoting teamwork in engineering design and manufacturing. Eur $\mathrm{J}$ Eng Educ 36(2):173-186. doi:10.1080/03043797.2011.573534

Oxford University (2014) Oxford english dictionaries (OED) online. http://oxforddictionaries.com/definition/english/value. Accessed 1 Jun 2014

Pahl G, Beitz W, Feldhusen J, Grote K (2007) Engineering design. A systematic approach, 3rd edn. Springer, London

Porter ME (1998) Competitive advantage: creating and sustaining superior performance. Free, New York

Postawa AB, Siewert M, Seliger G (2011) Mini factories for cocoa paste production. In: Seliger G (ed) Sustainable manufacturing. Shaping global value creation, September 28th-30th, Saint Petersburg, Russia. Universitätsverlag der TU Berlin, Berlin, pp 183-189

Schmutzenhofer H (1996) The IUFRO position on sustainable management of tropical forests. In: Dykstra DP, Heinrich R (eds) Forest codes of practice. Contributing to environmentally sound forest operations. Proceedings of an FAO/IUFRO meeting of experts on forest practices, December 11-14, Feldafing, Germany. Food and Agriculture Organization of the United Nations, Rome, Italy, pp 22-31

Schuh G, Gottschalk S, Höhne T (2007) High resolution production management. CIRP Ann Manuf Technol 56(1):439-442

Segreto T, Teti R (2014) Manufacturing. In: Laperrière L, Reinhart G (eds) CIRP encyclopedia of production engineering, 1st edn. Springer, Berlin, Germany, pp 828-830

Seliger G (2007) Sustainability in manufacturing. Recovery of resources in product and material cycles, Springer, Heidelberg, Germany

Seliger G (2011) Sustainability engineering by product-service systems. In: Hesselbach J, Herrmann C (eds) Glocalized solutions for sustainability in manufacturing. Proceedings of the 18th CIRP international conference on life cycle engineering, May 2-4, Braunschweig, Germany. Springer, Heidelberg, Germany, pp 22-28

Seliger G, Consiglio S, Zettl M, Kernbaum S (2004) Global product development (GPD)-best practice in modern engineering education. In: Seliger G (ed) Proceedings of the global conference on product development and life cycle engineering, September 29-October 1, Berlin, Germany. Uni-Edition, Berlin, Germany, pp 333-336

Shorrocks A, Davies JB, Lluberas R (2013) Global wealth databook. Credit Suisse, Zurich, Switzerland

Smith RL, Ruiz-Mercado GJ (2014) A method for decision making using sustainability indicators. Clean Technol Environ Policy 16(4):749-755

Suh NP, Do S (2000) Axiomatic design of software systems. CIRP Ann Manuf Technol 49(1):95-100. doi:10.1016/S00078506(07)62904-7

TRNC Ministry of Agriculture and Natural Resources (2011) Agricultural structure and production in Northern Cyprus 2010

Tseng MM, Wang C (2014) Modular design. In: Laperrière L, Reinhart G (eds) CIRP encyclopedia of production engineering, 1 st edn. Springer, Berlin, Germany, pp 895-897

UP ZRS (2009) Roadmap for sustainable energy use of olive residius. D2.2 joint report on 5 roadmaps. http://www.eaci-projects.eu/ iee $/$ fileshow.jsp?att_id $=24025 \&$ place $=$ pa\&url $=5 \% 201$ ocal $\% 20$ 
roadmaps $\% 20$ for $\% 20$ sustainable $\% 20$ use $\% 20$ of $\% 20$ olive $\% 20$ mills $\%$ 20residues.pdf\&prid=1628. Accessed 1 Jun 2014

Wiendahl H, ElMaraghy H, Nyhuis P, Zäh M, Wiendahl H, Duffie N, Brieke M (2007) Changeable manufacturing. classification, design and operation. CIRP Ann Manuf Technol 56(2):783-809. doi:10. 1016/j.cirp.2007.10.003
WWAP (2014) The United Nations world water development report 2014. (United Nations World Water Assessment Programme). Connor, Richard; Koncagül, Engin. United Nations Educational, Scientific and Cultural Organization (UNESCO), Paris, France 